\title{
A model for defining evacuation policies for emergency escape from buildings
}

\author{
Belarmino Adenso-Díaz ${ }^{1, a}$, Pilar González-Torre ${ }^{1}$, Verónica Ordóñez ${ }^{1}$ and Juan José del Coz ${ }^{2}$ \\ 1 Operations Management Department, University of Oviedo, Gijón, Spain \\ 2 Civil Engineering Department, University of Oviedo, Gijón, Spain
}

Received 30 October 2007, Accepted 15 February 2008

\begin{abstract}
Over the last 10 years, the need to guarantee safety in the habitability of buildings has led to the development of different models (which are usually classified either as optimization, simulation, or risk assessment approaches) that help define how urgent evacuation of the building should take place in the event of a fire or any other circumstance that requires such a measure. This paper presents an optimization model embedded in a simulation model that enables the user to define which evacuation routes should be used to minimize the time needed to evacuate all occupants. The system is presented here along with an experimental framework designed to assess the quality of the proposed solutions and the system's performance with respect to different types of buildings. Results analysis show improvements around $9 \%$ of the time needed to evacuate a building, using an experimental framework that considers three main factors: type of building, number of exit doors and capacity flow in the corridors.
\end{abstract}

Key words: Simulation; evacuation policies; optimization; emergency planning.

\section{Introduction}

The events that periodically appear in the world news highlight the importance that must be given to safety in buildings, as well as the difficulty of conducting an efficient evacuation should an emergency arise. Different computer assisted tools have appeared in recent years to help in the analysis of how to evacuate a building. These models permit the assessment of what will happen in a particular building when faced with the event of a fire or a forced evacuation due to any other cause.

These computer tools mostly address the problem from three distinct approaches [1]: simulation (see what occurs and test the alternatives), optimization (seek the best way of carrying out the evacuation), and risk assessment approaches (based on computer assisted tools, the main objective being only to assess exit conditions [2] or to obtain the total time need to evacuate the building [3]).

The research study presented here employs a mixed approach that simultaneously uses the first two paradigms, attempting to optimize the design of evacuation routes by the joint use of a heuristically determined simulation in order to fine tune egress parameters. The overall aim of this research study consists in providing those responsible for projecting and planning buildings with a simulation tool that allows them to study the egress movement of the occupants of a building during the

\footnotetext{
${ }^{a}$ Corresponding author: adenso@epsig.uniovi.es
}

process of evacuating people from a particular building, with the aim of assessing and comparing the feasibility and effectiveness of different evacuations plans. With this purpose in mind, a system was designed that is capable of automatically directing the search for the best parameters for defining the evacuation plan for a given building by means of iterative interaction with the defined simulator. The computer tool simulates the movements of the occupants in the building under analysis by means of the definition of rules and automatically defines the egress route that permits the highest speed of evacuation.

\subsection{Review of some previous models}

Two approaches have traditionally been used in designing evacuations in the event of an emergency:

a. Full/scale evacuation drills. This means using real people with similar characteristics to those who usually occupy the building and experimentally testing what will occur in the event of an emergency. This methodology presents several inconveniences, including those of an ethical nature (there may be casualties if an attempt is made to make the experiment realistic), as well as being very costly, since it is necessary to employ many people (if the aim is to obtain statistically significant results).

b. Strict application of predefined regulations. This consists in accepting or rejecting the proposed design on 
Table 1. Summary of the features of the reviewed evacuation models.

\begin{tabular}{|c|c|c|c|c|c|c|}
\hline Model & References & Objetive & $\begin{array}{l}\text { Evacuation } \\
\text { route }\end{array}$ & $\begin{array}{l}\text { Simulation } \\
\text { conditions }\end{array}$ & $\begin{array}{l}\text { Influence } \\
\text { egress }\end{array}$ & $\begin{array}{l}\text { Decisional } \\
\text { capacity }\end{array}$ \\
\hline 1. Allsafe & {$[1,2]$} & O.1 & R.3 & C.4 & E.2 & $\mathrm{D} .2$ \\
\hline 2. Aseri & {$[1,2]$} & 0.3 & R.1/R.4 & C. 4 & E.1 & D.1 \\
\hline $\begin{array}{l}\text { 3. Assisted Evacuation } \\
\text { Simulation }\end{array}$ & {$[4]$} & O.1 & R.4 & C. 4 & --- & --- \\
\hline 4. Bfires & {$[2,5]$} & 0.2 & R.5 & C. 4 & E.1 & D.1 \\
\hline 5. Bgraf & {$[2]$} & O.4 & R.5 & C. 4 & E.1 & D.1 \\
\hline 6. Crisp3 & {$[2,6]$} & O.3 & R.1.a & C.1/C.4 & E.1 & D.1 \\
\hline 7. Eescape & {$[1,2]$} & O.5 & R.3 & C.1 & E. 2 & D.2 \\
\hline 8. Egress & {$[1,2,7,8]$} & 0.3 & R.1.b & C. 4 & E.1 & D.1 \\
\hline 9. Egress Complexity model & {$[2,3]$} & 0.5 & R.6 & C. 1 & E.2 & D.2 \\
\hline 10. Egress Pro & {$[1,2]$} & 0.5 & R.3 & C. 3 & E. 2 & D.2 \\
\hline 11. E-Scape & {$[2]$} & O.3 & R.1.b & C. 4 & E.1 & D.1 \\
\hline 12. Evacnet4 & {$[1,2,8,9]$} & 0.6 & R.2 & C. 1 & E. 1 & D. 2 \\
\hline 13. Evacs & [1] & O.1 & R.4 & C. 1 & -- & D.2 \\
\hline 14. Evacsim & {$[2]$} & 0.3 & R.1.b & C. 4 & E.1 & D.1 \\
\hline 15. Exit89 & {$[1,2]$} & 0.2 & R.1/R.4 & C. 3 & E.1 & D. 2 \\
\hline 16. Exitt & {$[1,2,10]$} & O.4 & R.1.b & C. 4 & E. 2 & D.1 \\
\hline 17. Exodus & {$[1,2,4,8,11]$} & 0.3 & R.1.b & C. 4 & E. 1 & D.1 \\
\hline 18. Firecam & {$[2]$} & 0.7 & R.4 & C. 3 & --- & D.2 \\
\hline 19. Fpetool & {$[1]$} & O.1 & R. 4 & C. 3 & E.2 & D.2 \\
\hline 20. Gridflow & {$[1,2]$} & 0.3 & R.1/R.4/R.6 & C. 3 & E.1 & D. 2 \\
\hline 21. GSpaces & & 0.3 & R.5 & C. 2 & E.1 & D. 1 \\
\hline 22. Legion & {$[2]$} & 0.3 & R.5.a & C. 4 & E.1 & D.1 \\
\hline 23. Magnetic Model & {$[2]$} & 0.3 & R.1/R.4/R.5 & C. 2 & E.1 & D.1 \\
\hline 24. Myriad & {$[2]$} & 0.5 & R.1 & C. 1 & E.1 & D. 2 \\
\hline 25. Pathfinder & {$[1,2]$} & 0.3 & R.1/R.4 & C. 1 & E.1 & D.2 \\
\hline 26. Pedgo & {$[2,4]$} & 0.3 & R.4 & C. 2 & E.1 & D.1 \\
\hline 27. Pedroute y Paxport & {$[2]$} & 0.3 & R.1/R.2/R.3 & C. 2 & E.1 & D. 1 \\
\hline 28. Sgem & {$[2,15]$} & 0.3 & R.1.b & C. 2 & E.1 & D.1 \\
\hline 29. Simulex & {$[1,2,8,16,17]$} & 0.3 & R.1/R.4 & C. 2 & E.1 & D.2 \\
\hline 30. Steps & {$[1,2]$} & 0.3 & R.1.a/R.4 & C. 1 & E.1 & D.2 \\
\hline 31. Takahashi's Fluid Model & {$[2]$} & 0.3 & R.2 & C. 1 & E.1 & D.2 \\
\hline 32. Timtex & {$[2]$} & O.1 & R.1/R.4 & C.1 & E.2 & D. 2 \\
\hline 33. Vegas & {$[2]$} & --- & R.1.b & C. 4 & E.1 & D.1 \\
\hline 34. Wayout & {$[1,2]$} & --- & R.3 & C. 3 & E. 1 & D. 1 \\
\hline
\end{tabular}

the basis of its adaptation to a set of predefined regulations. In Spain, for example, this takes the form of a mandatory code (NBE-CPI-96, Norma Básica de Edificación, Condiciones de Protección contra Incendios, i.e., Basic Building Code, Fire Protection Conditions). However, it is unlikely that this procedure can take into account all the characteristic features of each building which condition the efficiency of its evacuation plan. These features may be classified under 4 categories: Configurational factors (layout, number of exits, width of exits, interior distances, etc.); Environmental factors (the debilitating effect of smoke, heat, gases, etc.); Procedural factors (the actions of the occupants of the building, their training, emergency signs, etc.); and Behavioral factors (the existence of families or groups in the building, initial reaction time, speed of movement, etc.).

To be able to consider all these factors that need to be taken into account in an evacuation process, the usual procedure is to develop computer assisted evacuation models. Following a review of the literature, 34 fire evacuation systems were identified (Tab. 1), which may be classified according to the following features:

- According to the objective of the program:

O.1. To calculate the total time need to evacuate the building.

O.2. To simulate the egress movement of evacuees, without being able to view the process. Here, only information relative to the positions occupied by the evacuees during the process and to the chosen evacuation route is obtained.

O.3. To simulate the egress movement of evacuees, with the possibility of viewing the process. Information is also obtained on the bottlenecks and jams produced during evacuation.

O.4. To study the decision-taking process of evacuees. O.5. To evaluate the exit conditions. 
- According to the evacuation route chosen by the occupants of the building:

R.1. The shortest route. Two, more specific options may exist in this case:

R.1.a. The shortest route modified according to the density of people.

R.1.b. The shortest route modified according to the behavior of the evacuees.

R.2. The route that minimizes evacuation time.

R.3. The only route possible given the geometry of the building.

R.4. The route defined by the user.

R.5. The route chosen according to the behavior of the evacuees. A more specific application is:

R.5.a. The route dictated by the behavior of the evacuees modified by the density of people.

R.6. Assigning a probability to each of the possible exits. The occupants will choose a particular exit on the basis of this probability.

- According to simulation conditions:

C.1. Does not consider the behavior of evacuees or the effects of the fire on the evacuation.

C.2. Considers the behavior of evacuees, but not the effects of the fire on the evacuation.

C.3. Considers the effects of the fire, but not the behavior of evacuees on the evacuation.

C.4. Considers the behavior of evacuees and the effects of the fire on the evacuation.

- According to the influence on egress movement owing to the presence of other occupants:

E.1. The egress movement of occupants affects the rest of the evacuees.

E.2. The egress movement of occupants does not affect the rest of the evacuees.

- According to the decisional capacity of occupants:

D.1. The occupants take decisions during the evacuation.

D.2. The occupants do not take decisions during the evacuation.

These programs may be divided into two major types: models that study how the movement of people is produced under normal non-emergency conditions (the precursors of which were Predtechenski and Milinksii [18], and subsequently Fruin [19], which, applied to areas with a large number of people and on stairs, gave rise to movement models such as PEDROUTE by Buckmann and Leather [20]); and evacuation models (which are more recent, some of the first studies being those by Stahl [5]). The latter type of model may in turn be classified into those that only consider deterministic movements (people are assumed not to think in a personal way, but react automatically to external stimuli, exiting as quickly as possible when the event occurs, at a specific speed, etc., which is how the model by Takashi et al. functions), and models which also consider physical features, those relating to the behavior of people, treating them as individual agents with different reaction times, preference for certain exits, etc. (the most paradigmatic example being the EXODUS software $[10,21])$. At the same time, several studies have shown how psychological factors have a major influence on the results of the evacuation [22].

In our model the goal pursued is to obtain the most appropriate evacuation policies for a given building, the result of the program being the route that the evacuees should follow in order to minimize the total time taken to completely evacuate the building. A deterministic approach is considered, the egress routes being defined by the use of heuristic algorithms linked to a simulation model for assessing the quality of the explored routes.

\section{Proposed model}

Figure 1 represents the scheme of the proposed system ${ }^{1}$. As can be seen, the building layout will be the starting point of the entire system. A graph including all the geometrical information on the building will be constructed on the basis of this layout (generated by module T1) in order to model all possible movements (see Fig. 2 for an example of a hotel floor). The graph will have 4 different types of nodes (access to rooms, widening doors inside a corridor, crossing of three or more corridors, and exit doors), the corridors being represented by the edges (see more details of implementations in Ordoñez et al. [23]). Additional data on the maximum capacity of corridors and maximum speed along them (as a function of the people in the corridor) and maximum flow crossing the doors and crossing are also needed for the simulation. In addition, the time for people to reach room doors (i.e., second by second, how many people will be passing through their room doors and trying to get into the corridor) is calculated by the room simulator (module T2 in Fig. 1), which will complete the input data for the simulation.

Note that an evacuation policy using these data will simply be an n-tuple indicating by means of each of the n nodes of type "crossing" which direction should be followed when arriving at that point. For instance, in Figure 2, given that crossing nodes are $\langle 18,19,21,23,24$, $26,27,28,29,30,31,32,33\rangle$, a solution would be the n-tuple $\langle 19,21,3,24,26,27,6,27,28,29,30,31,32\rangle$ which determines for each cross the "next corridor" to follow. Given this information and assuming determinism in the behavior of the evacuees, simulation (module T4) will consists in moving each person through the graph, second by second, considering the permissible speed and directions when arriving at a crossing, until everybody has exited the building, providing as output the time needed for its total evacuation.

The initial policy generator (T4) will be responsible for providing the simulator with the first strategy to

\footnotetext{
1 A freeware version of the system called SIMUDRILL can be downloaded from http://coruxa.epsig.uniovi.es/ $\$ \backslash$ sim\$adenso/file_d.html
} 


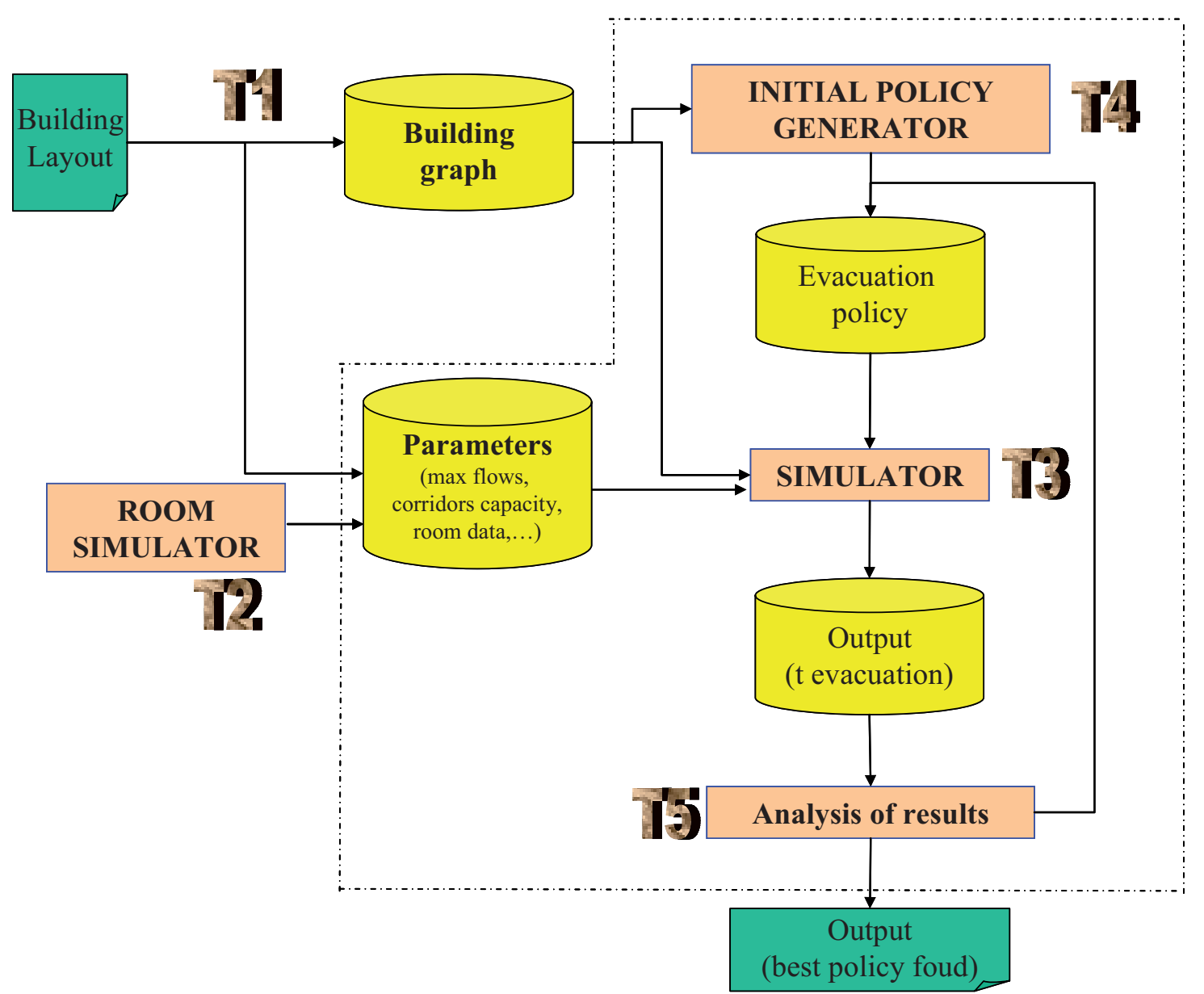

Fig. 1. Interrelationships among the modules of the designed system.

follow during evacuation (initial evacuation plan), which will be iteratively improved by considering the results of previous simulations (analyzed by module T5, which will be in charge of trying to find a solution that would minimize the required evacuation time).

As regards the logic of modules $\mathrm{T} 4$ and $\mathrm{T} 5$, the initial solution is generated using a heuristic procedure which has been proven to offer a good initial solution: from each room door in the building, we calculate the shortest path (using Dijkstra's algorithm) to any of the exit doors. The next corridor chosen at each crossing node defines the initial evacuation policy (in the case of a certain crossing node not being used by the shortest path from any room, Dijkstra's algorithm is used to find the shortest path from that crossing node to any exit door. This path then defines the next corridor for that crossing node).

The logic for optimization module T5 needs to be more complex. It comprises a local search procedure that explores the neighborhood of the current solution trying to find a policy with a shorter evacuation time. The algorithm starts with the current solution, and explores for each node of the type "crossing", which is the node with the slowest corridor that is in that solution. By forcing the escape from that node via a different corridor, the neighborhood of the current solution is defined, continuing the search until no further improvement is found. Figure 3 shows a pseudocode for the algorithm.

\section{System performance analysis}

An experimental framework was defined to analyze the performance of the proposed system, studying its behavior with respect to different factors as well as the improvement in quality achieved by means of the optimization phase. After a review of the system and its performance in preliminary experiments, three factors were identified that are considered likely to influence the quality of the obtained solutions: the type of building, the number of existing exits in the building, and the capacity (width) of its corridors.

The type of building refers to the fact that the rooms and corridors are all close to one another with a compact building design, or, to the contrary, that the rooms present a linear layout due to a longitudinal building design. The latter alternative may make it more difficult to evacuate the building in the case of an emergency if emergency exits do not also linearly exist along the length of the building. Two different types were considered in the 


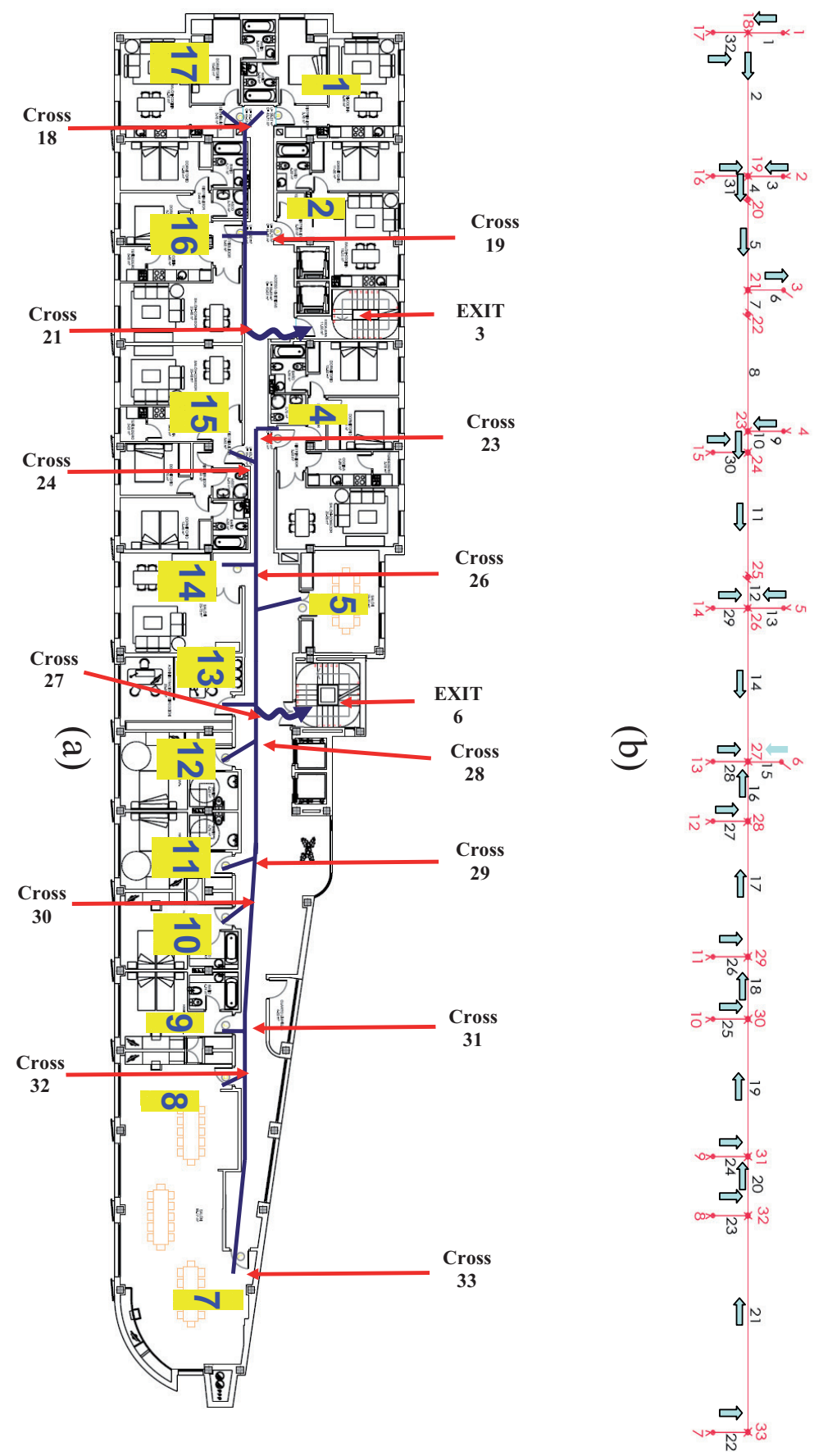

Fig. 2. Example of the layout of a hotel floor (a) and corresponding graph (b) input to the system. In the layout, the number of rooms and crossing nodes are indicated. In the graph, an example of evacuation policy is depicted.

experiments: a compact type building and a linear building (Fig. 4).

In the experimentation, all the buildings corridors have one of these lengths: $5,7,8$ or $25 \mathrm{~m}$ in the compact case, and 5 or $10 \mathrm{~m}$ in the linear one.

The maximum distance from any point in the building to the emergency exit is regulated in the legislation on the construction of buildings. However, a greater number of exits facilitates evacuation and therefore may also be a factor to take into account. Two levels were considered for this factor in the experiments: a building with few exits (only two) and one with many exits (four).

The graph that defines the layout of the building is fully determined with these two factors. It now only remains to define aspects such as: the maximum flow crossing doors and corridors crosses (in all cases a constant flow of 5 people per second in crosses, 4 people per second in exists when only two exists and 2 people per second in case of 4 exits were defined); the time for people reaching rooms doors (in all cases, a schedule of 2 people 
1. Let $\mathrm{S}_{\text {cur }}$ be the current solution and $\mathrm{T}_{\mathrm{Scur}}$ its evacuation time.

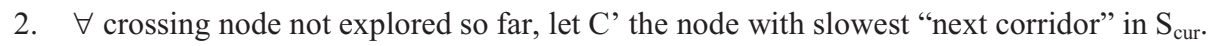

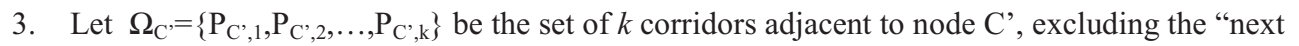
corridor" in $\mathrm{S}_{\text {cur. }}$.

4. $\forall \mathrm{P} \in \Omega_{\mathrm{C}}$, we build the solution $\mathrm{S}_{\mathrm{P}}$ obtained from $\mathrm{S}_{\text {cur, }}$ by forcing $\mathrm{P}$ as "next corridor" in node $\mathrm{C}$ '. Calculate by calling simulation module its evacuation time $\mathrm{T}_{\mathrm{Sp}}$.

5. Let $\mathrm{P}^{\prime} \in \Omega_{\mathrm{Cr}}$ the corridor with smallest $\mathrm{T}_{\mathrm{Sp}}$.

IF $\mathrm{T}_{\mathrm{Sp}},<\mathrm{T}_{\text {Scur }} \rightarrow$ GOTO $\underline{\mathbf{6}}$ (*a better solution than $\mathrm{S}_{\text {cur }}$ was found*)

ELSE $\rightarrow$ GOTO $\underline{7}$ (*continue exploration from $\mathrm{S}_{\text {cur }}$ or a solution worse than $\mathrm{S}_{\text {cur }}{ }^{*}$ )

6. Update $\mathrm{S}_{\text {cur }}:=\mathrm{S}_{\mathrm{p}}$;

GOTO $\underline{2}$

7. IF all crossing nodes have been already explored

$$
\begin{aligned}
& \text { IF } \left.\mathrm{T}_{\mathrm{Sp}},>1.10 * \mathrm{~T}_{\text {best solution found so far }}\right) \rightarrow \mathrm{GOTO} \underline{\mathbf{8}} \text { (* end of exploration*) } \\
& \mathrm{ELSE} \rightarrow\left\{\mathrm{S}_{\mathrm{cur}}:=\mathrm{S}_{\mathrm{p}}\right. \text {; } \\
& \text { GOTO } \underline{2} \text { \} (*continue exploration from the new } \mathrm{S}_{\text {cur }}{ }^{*} \text { ) }
\end{aligned}
$$

ELSE $\rightarrow$ GOTO $\underline{\mathbf{2}}$ (*continue exploration of neighborhood of original $\mathrm{S}_{\mathrm{cur}}{ }^{*}$ )

8. Output the best solution found so far; END.

Fig. 3. Pseudocode for the optimization phase of the system.

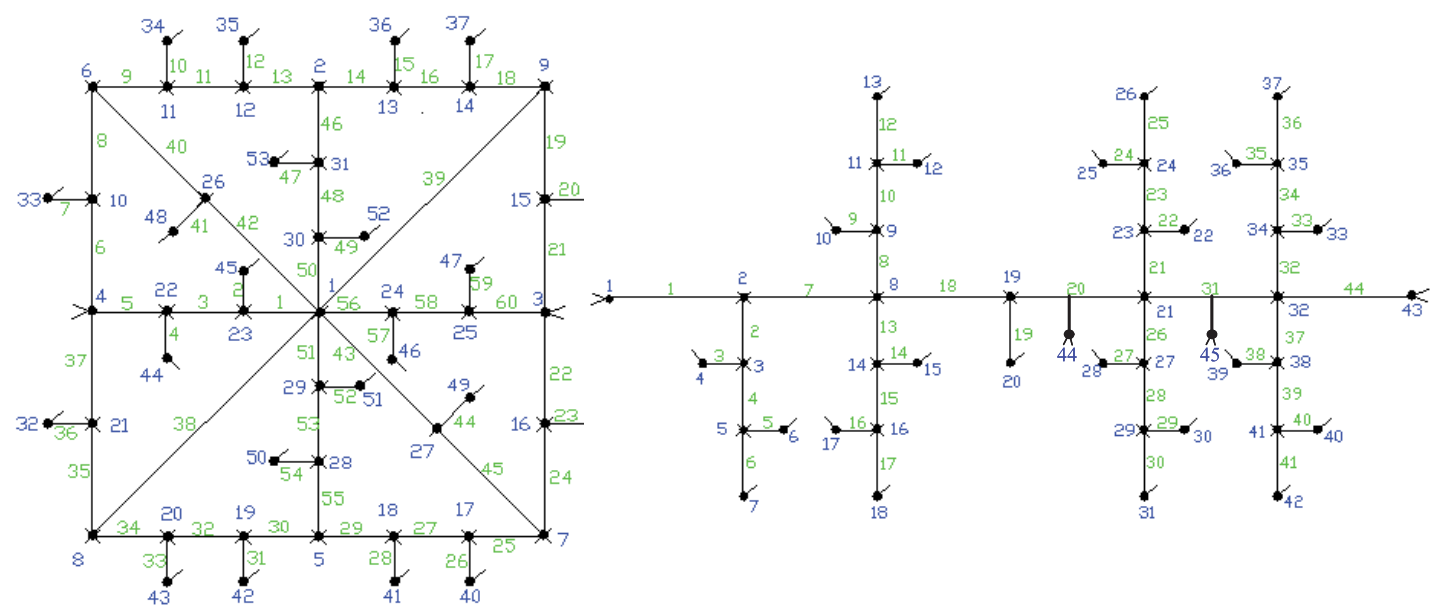

(a)

(b)

Fig. 4. Basic structure of the (a) compact and (b) linear buildings used in the experiments, indicating each of their nodes and edges. Exit nodes in compact case are number 3, 4, 8 and 9 (3 and 4 when only two exits), and in the linear case nodes 1, 43, 44 and 45 (1 and 43 when only two exits).

reaching the door in second 5 was defined for rooms, and 3 people in second 5,4 in second 6,5 in second 7,4 in second 8,3 in second 9 and 1 in second 10 for all meeting rooms). Regarding the speed of evacuation in the corridors or their maximum capacity, these factors will be defined on the basis of the number of people who fit into a linear meter of corridor (corridor width). Five levels were considered for this factor: $1,2,3$, 4, or 5 people per linear meter of corridor. In this way, the maximum capacity is calculated as the product of the corridor length times this factor, and the maximum running speed in the corridors, as some constants depending in the number of people in the corridor and its length (see Table 2).

Experiments were carried out for $2 \times 2 \times 5=20$ different buildings and scenarios, varying the levels of the
3 factors under consideration. The descriptive results of this experimentation (the evacuation time given by the initial solution and that given by the optimized solution) are presented in Table 3.

\subsection{Analysis of the results}

To verify whether the results obtained after the optimization are better than those obtained initially, the type of distribution of the variable under study were previously studied. By means of the Kolmogorov-Smirnov test, it was shown that both the data from the initial solution $(Z=0.943$, bilateral significance $=0.336)$ and those corresponding to the optimized solution $(Z=0.987$, bilateral significance $=0.284$ ) are normally distributed, 
Table 2. Evacuation speed $(\mathrm{m} / \mathrm{s})$ as a function of the number of people in a corridor and its length.

\begin{tabular}{|c|c|c|c|c|c|}
\hline Number of people in the corridor & $\begin{array}{l}5 \mathrm{~m} \\
\text { corridor }\end{array}$ & $\begin{array}{c}7 \mathrm{~m} \\
\text { corridor }\end{array}$ & $\begin{array}{c}8 \mathrm{~m} \\
\text { corridor }\end{array}$ & $\begin{array}{c}10 \mathrm{~m} \\
\text { corridor }\end{array}$ & $\begin{array}{c}25 \mathrm{~m} \\
\text { corridor }\end{array}$ \\
\hline 1 person $-1 / 4$ of maximum capacity of the corridor & 5 & 6 & 7 & 6 & 8 \\
\hline $\begin{array}{l}1 / 4 \text { of maximum capacity of the corridor }-1 / 2 \text { of } \\
\text { maximum capacity of the corridor }\end{array}$ & 2 & 3 & 4 & 4 & 5 \\
\hline $\begin{array}{l}1 / 2 \text { of maximum capacity of the corridor - corridor } \\
\text { full of people }\end{array}$ & 1 & 1 & 1 & 1 & 1 \\
\hline
\end{tabular}

Table 3. Descriptive statistics of the variables involved in the experiments.

\begin{tabular}{|c|c|c|c|}
\hline Type of solution & Factor/Levels & $\begin{array}{c}\text { Evacuation time } \\
\text { Average (s) }\end{array}$ & $\begin{array}{c}\text { Evacuation time } \\
\text { Standard deviation (s) }\end{array}$ \\
\hline \multirow[t]{13}{*}{ Initial } & & 38.15 & 18.88 \\
\hline & Layout type: & & \\
\hline & Compact & 32.60 & 12.01 \\
\hline & Linear & 43.70 & 23.23 \\
\hline & Number of exits: & & \\
\hline & Two & 42.20 & 19.48 \\
\hline & Four & 34.10 & 18.34 \\
\hline & Corridor capacity: & & \\
\hline & 1 people/m & 69.50 & 19.33 \\
\hline & 2 people/m & 36.75 & 8.85 \\
\hline & 3 people/m & 30.75 & 6.34 \\
\hline & 4 people/m & 27.50 & 5.20 \\
\hline & 5 people/m & 26.25 & 3.40 \\
\hline \multirow[t]{13}{*}{ After optimization } & & 34.80 & 16.35 \\
\hline & Layout type: & & \\
\hline & Compact & 32.20 & 11.70 \\
\hline & Linear & 37.40 & 20.31 \\
\hline & Number of exits: & & \\
\hline & Two & 40.10 & 19.20 \\
\hline & Four & 29.50 & 11.55 \\
\hline & Corridor capacity: & & \\
\hline & 1 people/m & 61.00 & 18.81 \\
\hline & 2 people/m & 34.50 & 7.42 \\
\hline & 3 people/m & 29.00 & 4.55 \\
\hline & 4 people/m & 25.00 & 4.08 \\
\hline & 5 people $/ \mathrm{m}$ & 24.50 & 4.12 \\
\hline
\end{tabular}

thus allowing the use of parametric tests in the statistical analyses.

To compare the results given by the initial and optimized solutions, an analysis of the initial correlation shows a strong positive relation between the two crossed variables $(R=0.944)$, while the t-test for paired data $(t=2.340$, bilateral significance $=0.030)$ confirms the existence of statistically significant differences between the average values of the two variables. From Table 3, it can be seen that an average improvement in evacuation time of $8.78 \%$ is obtained, thus verifying the effectiveness of the optimization algorithm. Computational times for the experimentation are nearly negligible (less than one second).

To test the effects of the 3 considered factors on the performance of the optimization phase, a Mann-Whitney's test was carried out for the case of the type of building and the number of exits (which only have two levels), considering as the analysis variable the ratio between the optimized solution an the initial one. Test results show significative differences between the results obtained after the optimization phase depending on the type of layout $(Z=-3.538$, bilateral significance near 0 ), while no differences are shown for the factor number of exits $(Z=-0.115$, bilateral significance 0.908$)$. The appropriate number of exit doors on the floor depends on the scale of the floor and the total length of routes [24], although their widths also affect the survival rates [17]. According to the literature, other factors having influence on the successful evacuation are the good knowledge by the people of the building layout, the existence of good instructions and signals to follow the evacuation route [18], the queues length [17] or the panic syndrome [24].

A Kruskal Wallis' test, again for the ratio of improvement after optimization phase, was used to analyze the effects of the capacity of the corridors on evacuation time. The results obtained $\left(\chi^{2}=0.884\right.$, signification 0.927$)$ show no significant differences among the five levels taken into consideration. However, Table 3 shows that, without any other variation in the data, the greater the capacity of the corridor, the lower the time needed to evacuate the building, obtaining an improvement in evacuation time of 
almost $60 \%$ between the two simulated extremes ( 1 person per meter and 5 people per meter).

\section{Conclusions}

To date, several approaches have been used to define the policies for evacuating a building. Some of them studied the fire advance $[25,26]$, while some other $[9,11,15,17,21,24,27]$ studied the people behavior when evacuating a building. However in this paper we propose a new approach to define the best evacuation route, after analyzing, from an optimization point of view, the different alternative routes from each corridor cross to the different exit doors. This paper presents a model based on the definition of an initial policy that is subsequently improved iteratively by means of a heuristic algorithm linked to the simulator that assesses the quality of the solutions that are being explored. The proposed model uses a network to represent the building that consists of a set of nodes (rooms) connected by arcs (corridors). The progressive motion and behavior of each individual is determined by a set of heuristics rules.

This model was tested using an experimental framework which considers 3 factors (type of building, abundance of exit doors from the building, and the capacity of the corridors). Simulations were carried out on 20 different scenarios which allowed us to confirm that the optimization phase achieves a statistically significant average improvement of $8.72 \%$ in the evacuation time offered by the initial starting-out solutions, in addition to the influence of the 3 factors on the performance of the algorithm. Future research should analyze the goodness of the generated solutions versus other heuristic procedures for generating initial solutions.

\section{Acknowledgements}

This research was funded by the Spanish Ministry of Infrastructures, contract number MFOM-06-2.

\section{References}

1. E. Kuligowski, R. Peacock, A review of building evacuation models, National Institute of Satndards and Technology, Technical Note 1471, 2005

2. S. Olenick, D. Carpenter, Journal of Fire Protection Engineering 13, 87 (2003)

3. H.A. Donegan, A.J. Pollock, I.R. Taylor, 1994, Egress Complexity of a Building, in Proceedings of Fourth International Symposium on Fire Safety Science, edited by T.l. Kashiwagi, 601-12

4. M. Jafari, I. Bakhadyrov, A. Maher, Technological advances in evacuation planning and emergency management: current state of the art. U.S. Department of Transportation. Center for Advanced Infrastructure and Transportation, Report n EVAC-RU4474, 2003
5. F. Stahl, Fire Technology 18, 49 (1982)

6. J.N. Fraser-Mitchell, An Object-Oriented Simulation (CrispII) for Fire Risk Assessment, in Proceedings of the Fourth International Symposium of Fire Safety Science, edited by T. Kashiwaga, 1994, pp. 793-804

7. H.W. Hamacher, S.A. Tjandra, Mathematical Modelling of Evacuation Problems: A State of the Art. Berichte des Fraunhofer ITWM, 2001, No. 24

8. G. Santos, B.E. Aguirre, A critical review of emergency evacuation simulation models. University of Delaware. Disaster Research Center, Preliminary Paper 339, 2004

9. T.M. Kisko, R.L. Francis, Fire Safety Journal 9, 211 (1985)

10. B. Levin, Exitt, a simulation model of occupant decisions and actions in residential fires, in Proceedings of the Second International Symposium on Fire Safety Science, edited by T. Wakamatsu, Y. Hasemi, A. Seizawa, P. Seeger, P. Pagni, C. Grant, 1989, pp. 561-570

11. E.R. Galea, J.M.P. Galparsoro, Fire Safety Journal 22, 341 (1994)

12. E.R. Galea, M. Owen, Emergency Egress From Large Buildings Under FIRE conditions Simulated Using The Exodus Evacuation Model, in Proceedings of the Seventh International Fire Science and Engineering Conference Intertlam'96, edited by C. Franks, S. Grayson, 1996, $711-720$

13. S. Gwynne, E.R. Galea, P.J. Lawrence, M. Owen, L. Filipidis, Further Validation of the building Exodus Evacuation Model Using the Tsukuba Dataset, CMS Press, 1998, No. 9, XIM:31

14. S. Gwynne, E.R. Galea, P.J. Lawrence, L. Filipidis, Fire Safety Journal 36, 327 (2001)

15. S.M. Lo, Z. Fang, P. Lin, G.S. Zhi, Fire Safety Journal 39, 169 (2004)

16. P. Thompson, J. Wu, E.W. Marchant, Fire Engineers Journal 56, 6 (1996)

17. P. Thompson, E.W. Marchant, Fire Safety Journal 24, 149 (1995)

18. V.M. Predtechenskii, A.I. Milinskii, Planning for Foot Traffic in Buildings, New Delhi: Amerind Publishing Co. Pvt. Ltd, 1978

19. J.J. Fruin, Pedestrain Planning and Design, Mobile, AL: Elevator World, Inc., 1987

20. L.T. Buckmann, J. Leather, Traffic Engineering and Control 35, 373 (1994)

21. M. Owen, E.R. Galea, P.J. Lawrence, Journal of Fire Protection Engineering 8, 65 (1996)

22. N.R. Johnson, W.E. Feinberg, Journal of Environmental Psychology 17, 123 (1997)

23. V. Ordoñez, B. Adenso-Díaz, P. González-Torre, J.J. del Coz, Simulation of performance of evacuation policies in a building, Proceedings of the First International Conference on Multidisciplinary Design Optimization and Applications, ASMDO, 17-20 April, 2007 (Besancon, France)

24. H. Notake, M. Ebihara, Y. Yashiro, Safety Science 38, 127 (2001)

25. G. Hadjisophocleous, Z. Fu, S. Fu, Ch. Durcher, Journal of Fire Protection Engineering 17, 185 (2007)

26. K. Remesh, K.H. Tan, Journal of Fire Sciences 25, 321 (2007)

27. T.T. Pires, Fire Safety Journal 40, 177 (2005) 